\title{
Development of High-voltage Testing System Based on Power Frequency Converter Used in Partial Discharge Tests of Potential Transformers
}

\author{
Tongpian Prombud and Peerawut Yutthagowith* \\ Faculty of Engineering, King Mongkut's Institute of Technology Ladkrabang, \\ 1 Soi Chalongkrung 1, Ladkrabang, Bangkok, 10520 Thailand
}

(Received June 30, 2019; accepted December 26, 2019)

Keywords: low-pass filter, high-voltage tests, partial discharge, potential transformer, PWM frequency converter

We present the development of a high-voltage (HV) testing system based on a power frequency converter in $\mathrm{HV}$ and partial discharge (PD) tests of a potential transformer (PT). The converter with the proper filter is utilized as a low-voltage source connected with a HV transformer in the HV and PD tests. The converter is composed of a three-phase rectifier and a power converter based on pulse width modulation (PWM) with a unipolar switching technique. The vital problem in the HV and PD tests is that a converter with a high rate of rise and fall of voltage switching always generates a high noise level that affects the background noise in the PD test. In some PD tests, the noise level is higher than the acceptable level of the PD test requirement in HV equipment such as PTs and distribution transformers. It will be advantageous if an efficient PD testing system based on a power frequency converter can be developed for such tests. In this paper, the proper filter was analyzed and developed to meet the following requirements: the applied HV difference (root mean square voltage and peak voltage $/ \sqrt{2}$ ) to the test object and its total harmonic distortion should be less than $5 \%$, and the background noise level in the PD tests should be less than half the acceptable PD level of such HV equipment specified by the relevant standards. In the case of the oil-type PT, the acceptable PD level is only $5 \mathrm{pC}$, so it is difficult to find a low-cost commercial frequency converter that satisfies this requirement. To verify the developed system, the performance characteristics of the developed converter have been investigated in terms of the background noise in the PD test, the total harmonic distortion of output voltage from the HV testing transformer side, and the input power consumption. The characteristics of the proposed and developed system are analyzed, and experimental results agree well with the simulation ones. The developed system can generate an output voltage of high quality that satisfies the standard requirement. At the test voltage of $40 \mathrm{kV}_{\text {rms }}$, the total harmonic distortion voltage $\left(T H D_{v}\right)$ is less than $2 \%$ and the background noise is less than $2.5 \mathrm{pC}$. Moreover, the proper switching frequency and amplitude modulation index $\left(m_{a}\right)$ are investigated, and it is found that the switching frequency from 1 to $20 \mathrm{kHz}$ and $m_{a}$ of 0.8 and 1 do not affect the background noise level or the $T H D_{v}$, and the switching frequency from 1 to $4 \mathrm{kHz}$ and $m_{a}$ of 1 are the best conditions since the input power ${ }^{*}$ Corresponding author: e-mail: peerawut.yu@kmitl.ac.th https://doi.org/10.18494/SAM.2020.2531 
consumption is the lowest. In addition, the developed system has been tested in the partial test of a real PT and found to be feasible. With its promising performance, the developed system is an attractive choice for use in HV and PD tests.

\section{Introduction}

The most important high-voltage (HV) test is the verification of the performance of HV equipment in design and construction processes. Examples of such tests are insulation voltage withstand test, power loss measurement, dielectric loss measurement, and partial discharge (PD) measurement.

According to IEC 60270:2000, ${ }^{(1)}$ PDs are defined as localized electrical discharges that only partially bridge the insulation between conductors, and they are caused by local electrical stress concentrations in the insulation or on the surface of the insulation. Generally, such discharges appear as pulses having durations of less than $1 \mu \mathrm{s}$. PD measurement is the most important test used in the evaluation of insulation performance and life. The PDs are classified into three main types. The first type of PD, named corona discharge, can occur in areas having sharp edges and high electric field stress. The second type originates from defects of the internal insulation material, such as bubbles and voids. If these defects have lower insulation levels than the main insulation material, under sufficient electrical field stress, PD can occur. The last PD type, called surface discharge, occurs at the boundary between two materials.

As the simplest way to generate HV for HV testing, ${ }^{(2)}$ a voltage regulator connected with a power source from a low-voltage grid or a generator is applied to a HV testing transformer at the low-voltage side. The HV from the transformer is applied to a test object. Because of the nonlinear characteristic of the equipment for the power electronics application, disturbance is generated in the electrical system, and it sometimes causes power quality problems. According to IEC $60060-1,{ }^{(3)}$ the testing voltage should be an almost purely sinusoidal waveform of which $T H D_{v}$, defined by Eq. (1), and different voltage ( $D V$; peak voltages divided by $\sqrt{2}$ and RMS voltage) should be less than $5 \%$.

$$
T H D_{v}=\frac{1}{V_{p 1}} \sqrt{\sum_{i=2}^{50} V_{p i}^{2}}
$$

Here, $V_{p 1}$ is the peak voltage of the fundamental frequency and $V_{p i}$ is the peak voltage of the $i$ th harmonic frequency. Figure 1 shows the test voltage applied to the potential transformer (PT) and PD pattern during the HV test. It is found that the $D V$ and $T H D_{v}$ are higher than $5 \%$. To avoid voltage distortion and satisfy the standard requirement, a voltage filter is also applied to the system.

For the HV test of PTs and to confirm the insulation performance of the test object, it is necessary to raise the voltage to higher than the rating voltage. If the applied testing voltage with the rated frequency is used in the test, the core saturation of the PT can occur and the applied voltage may be distorted. For a better understanding, an example case should be 


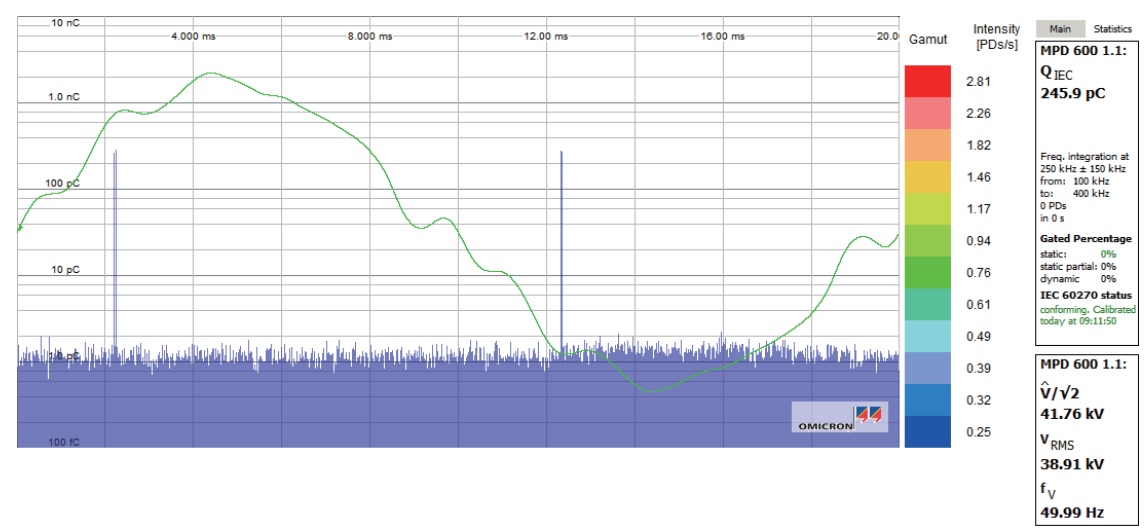

Fig. 1. (Color online) Test voltage waveform and the PD pattern during the HV test.

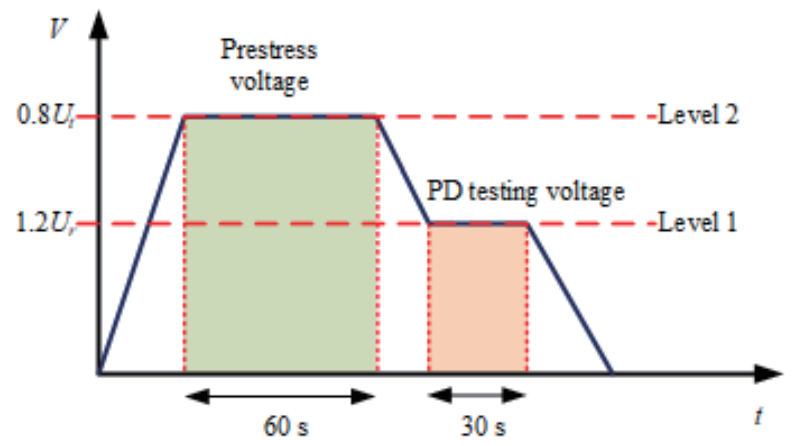

Fig. 2. (Color online) Procedure of voltage application for the PD test of PTs.

considered. For the PD test of a PT with the rating voltage $\left(U_{r}\right)$ of $24 \mathrm{kV}$, the prestress voltage condition with a withstand voltage $\left(U_{t}\right)$ of $80 \%$ is applied to the PT, and then the testing voltage is decreased to the level of $1.2 U_{r}(28.8 \mathrm{kV})$ to record the PD activity. The procedure of applying voltage in the PD test is shown in Fig. 2. Therefore, the saturation of the iron core of PT is avoided by applying voltage with a frequency higher than the rated frequency of the PT. If the voltage with a power frequency of $50 \mathrm{~Hz}$ is applied to the $\mathrm{HV}$ side of the PT, the saturation effect of the PT affects the distortion of the applied voltage waveform, as shown in Fig. 1. The $D V$ and $T H D_{v}$ are higher than $5 \%$. Therefore, to avoid the core saturation effect, a test voltage with a frequency higher than twice the power frequency is necessary in the test; the frequency of $200 \mathrm{~Hz}$ is a good candidate for all PTs with the rating frequencies of 50 and $60 \mathrm{~Hz}$.

Nowadays, power electronics technology has been applied in many practical fields, such as home appliances, automotives and transaction, renewable energy, and HV transmission and distribution systems. In HV generation for testing, the power electronics converter is a powerful and efficient tool for $\mathrm{AC} / \mathrm{DC}, \mathrm{DC} / \mathrm{AC}$, and $\mathrm{AC} / \mathrm{AC}$ power conversion. However, the crucial problem of the application of the power converter in the $\mathrm{PD}$ test is the interference signal originating from the fast switching of power electronic devices. It causes the PD detection system to have background noise much higher than the acceptable level. For example, in the PD tests of PTs insulated with oil, the acceptable PD level is only $5 \mathrm{pC}$. Consequently, the testing 
system including the PD detection system should have a background noise level below $50 \%$ of the acceptable PD level $(2.5 \mathrm{pC})$. Most commercial power converters have an additional filter for eliminating undesired harmonic voltages and obtaining voltage waveforms close to a pure sinusoidal wave. However, the filter cannot eliminate the interference in the PD measurement completely, leading to the background noise in the PD test being higher than the acceptable level.

In this study, the PD testing system composed of a power frequency converter, an additional filter, an HV transformer, and a PD detection system was analyzed, designed, developed, and tested to confirm the validity of the PD test of PTs.

\section{Development of HV Testing System for PD Tests}

The developed system with the equivalent circuit shown in Fig. 3 is composed of a power frequency converter, an additional filter, an HV testing transformer, and a PD detection system.

\subsection{Power frequency converter}

The power frequency converter based on the H-bridge configuration, as shown in Fig. 4, was developed. The converter is composed of a rectifier and $\mathrm{H}$-bridge insulated-gate bipolar transistors (IGBTs) controlled by a unipolar pulse width modulation (PWM) technique.

The unipolar PWM technique ${ }^{(4-7)}$ is based on the operation of four control switches, S1, S2, $\mathrm{S} 3$, and S4, as shown in Table 1. The AC output voltage waveform can instantaneously take one of the following three voltage levels: $+V_{d c},-V_{d c}$, or 0 .

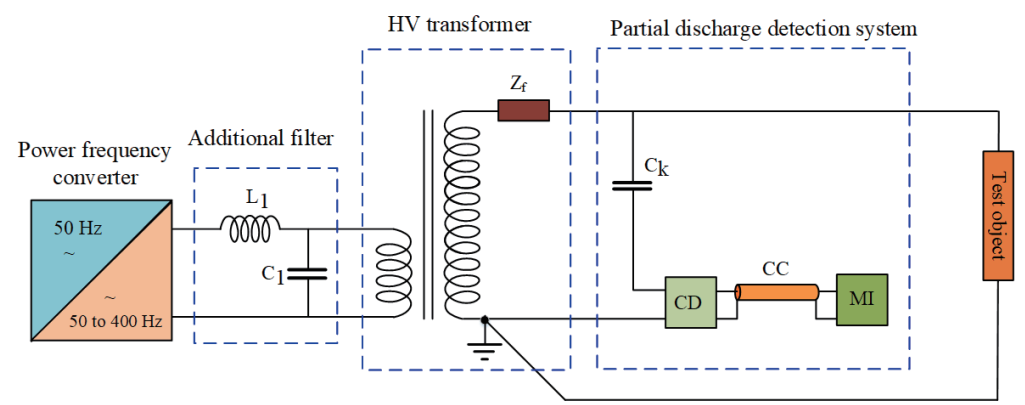

Fig. 3. (Color online) PD testing system.

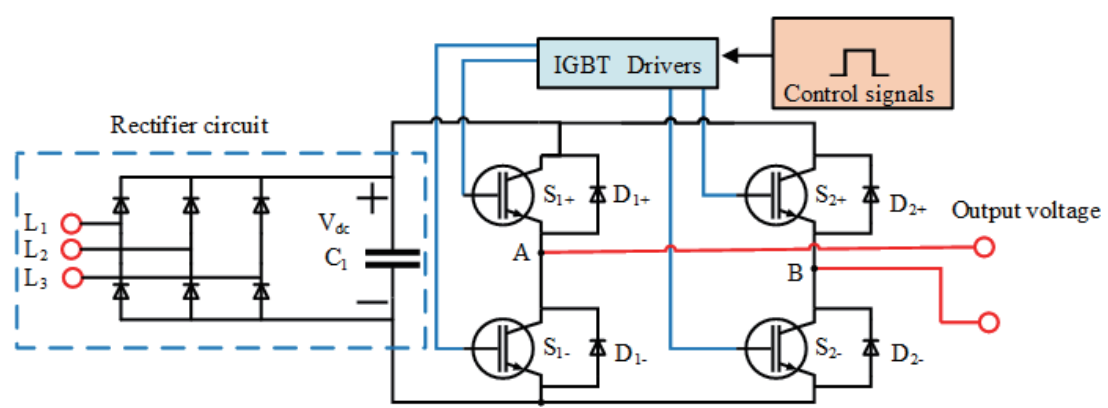

Fig. 4. (Color online) HV source power converter generator. 
The controlled and AC reference voltage waveforms are shown in Fig. 5(a), and the output signal is shown in Fig. 5(b).

\subsection{PD detection system}

The developed PD detection system is composed of a coupling capacitor $\left(\mathrm{C}_{\mathrm{k}}\right)$ connected in series with the measuring impedance [coupling device (CD)]. The capacitance $C_{k}$ was selected to be $1 \mathrm{nF}$, and the measuring impedance was designed to have the band-pass characteristic with the equivalent circuit shown in Fig. 6 and the transfer impedance characteristic with the low and high cutoff frequencies of $30 \mathrm{kHz}$ and $20 \mathrm{MHz}$, as shown in Fig. 7.

Table 1

Switch states in full-bridge single-phase voltage source inverter unipolar PWM.

\begin{tabular}{cccccc}
\hline \multirow{2}{*}{ State } & \multicolumn{2}{c}{ Switch conduction status } & \multicolumn{2}{c}{ Conduction status of IGBT and diode } & \multirow{2}{*}{$V_{0}$} \\
\cline { 2 - 4 } & ON & OFF & $I_{0}>0$ & $I_{0}<0$ & \\
\hline 1 & $S_{1+}, S_{2-}$ & $S_{1-}, S_{2+}$ & $S_{1+}, S_{2-}$ & $D_{1+}, D_{2-}$ & $V_{d c}$ \\
2 & $S_{1+}, S_{2+}$ & $S_{1-}, S_{2-}$ & $S_{1+}, D_{2+}$ & $D_{1+}, S_{2+}$ & 0 \\
3 & $S_{1-}, S_{2+}$ & $S_{1+}, S_{2-}$ & $D_{1-}, D_{2+}$ & $S_{1-}, S_{2+}$ & $-V_{d c}$ \\
4 & $S_{1-}, S_{2-}$ & $S_{1+}, S_{2+}$ & $D_{1-}, S_{2-}$ & $S_{1-}, D_{2-}$ & 0 \\
\hline
\end{tabular}

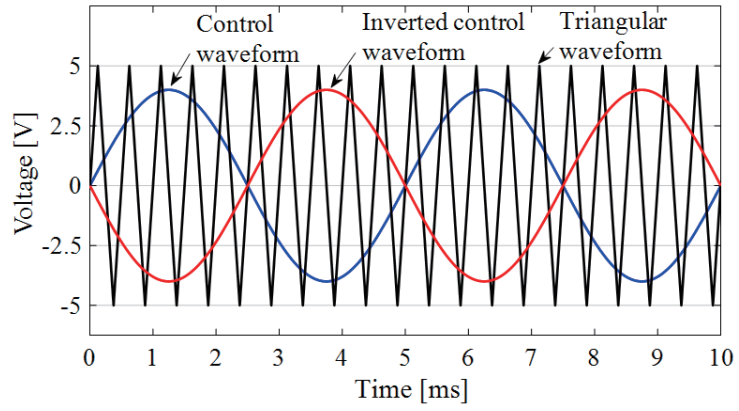

(a)

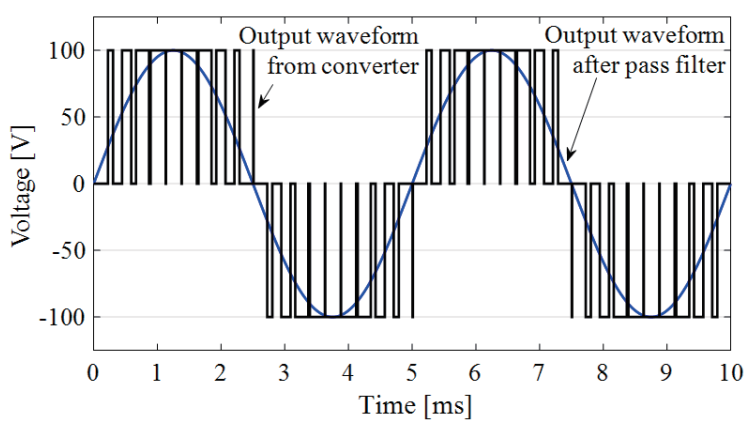

(b)

Fig. 5. (Color online) Generated PWM waveform from the PWM converter. (a) PWM in the unipolar converter. (b) Output waveform of the power converter.

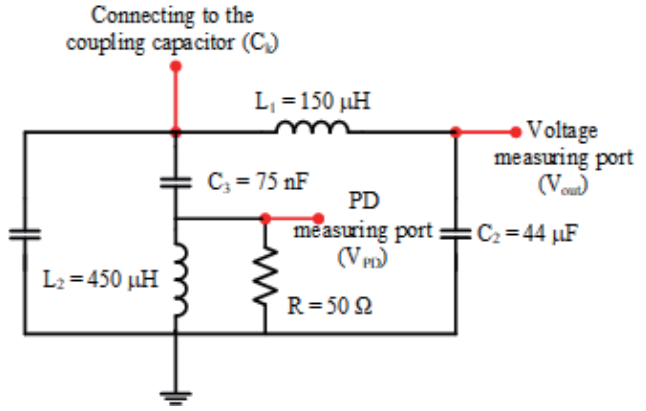

Fig. 6. (Color online) Equivalent circuit of the measured impedance or the $\mathrm{CD}$.

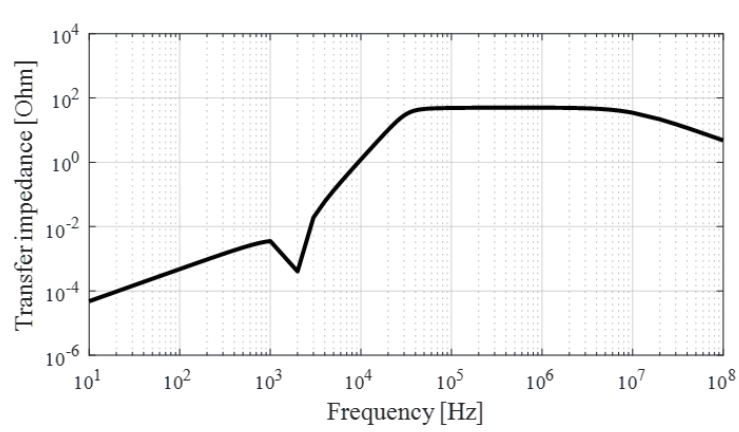

Fig. 7. Transfer impedance of the measured impedance in the frequency domain. 
The equivalent circuit of the PD detection system with the HV testing transformer is shown in Fig. 8. The transfer function of the output voltage $\left(V_{\text {out }} / V_{\text {in }}\right)$ can be calculated as shown in Fig. 9, which shows that this transfer function has the characteristic of a low-pass filter. The cutoff frequency is about $1200 \mathrm{~Hz}$. It is noted that the total impedance of the HV testing transformer with the rating of $460 \mathrm{~V} / 75 \mathrm{kV}$ and $40 \mathrm{kVA}$ is transferred to the HV side of the transformer. The circuit parameters are described in Fig. 8 and the PT under test ${ }^{(8,9)}$ or the test object can be represented well with high impedance, which has no effect in the test circuit. When the simulated pulse of $2.5 \mathrm{pC}$ is injected to the system, the peak voltage detected at the PD measuring port is $5 \mathrm{mV}$, as shown in Fig. 10.

For a better understanding of the problem of cooperation with the PWM frequency converter, we should consider the case in which the $200 \mathrm{~Hz}$ PWM voltage of $100 \mathrm{kV}$ with the switching frequency of $3.2 \mathrm{kHz}$ is supplied to the system without the additional filter as shown in Fig. 8. The voltage across the test object has small oscillation, as shown in Fig. 11, and its $T H D_{v}$ is $0.93 \%$. The PWM voltage also affects the voltage at the PD measuring port, which shows a peak voltage of $570 \mathrm{mV}$, as shown in Fig. 12, which is much higher than that $(5 \mathrm{mV})$ obtained with a $2.5 \mathrm{pC}$ simulated pulse. Therefore, the means of mitigating the interference from the PWM frequency converter is required for the PD test in real practice. In this paper, the additional filter is proposed to connect at the LV side of the HV testing transformer. ${ }^{(10)}$ The analysis of the additional filter will be presented in the next subsection.

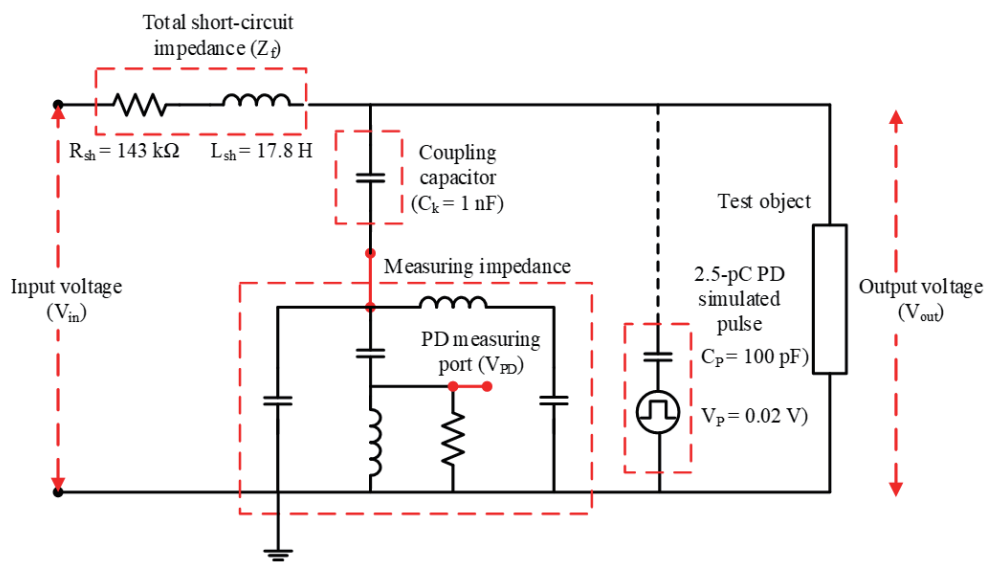

Fig. 8. (Color online) Equivalent circuit of the PD testing system without the additional filter.

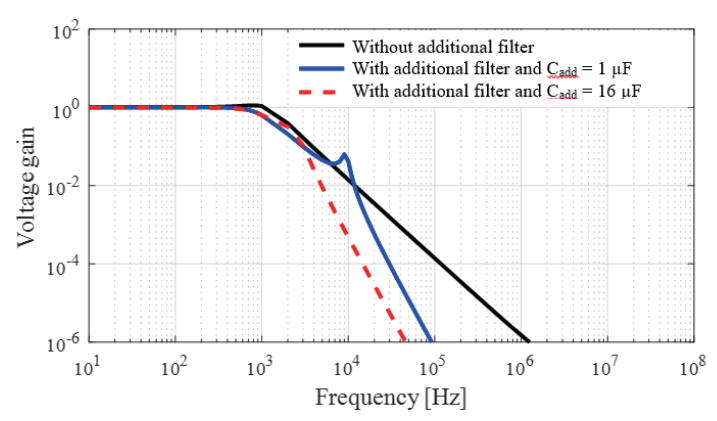

Fig. 9. (Color online) Transfer function of the output voltage without and with the additional filter.

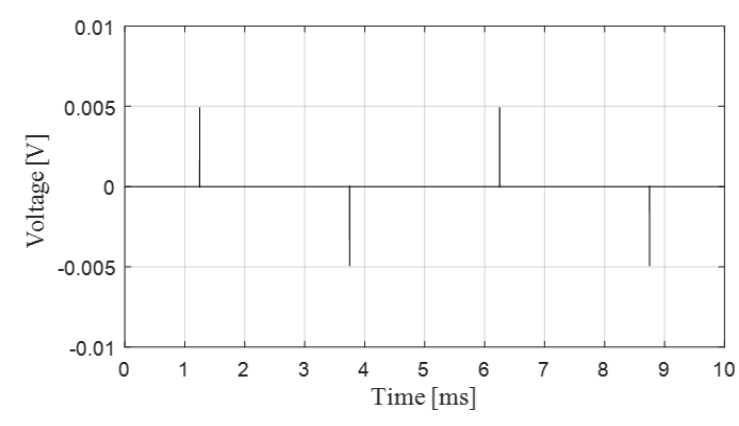

Fig. 10. Voltage at the PD measuring port in the case of $2.5 \mathrm{pC}$ simulated pulse injection to the system. 


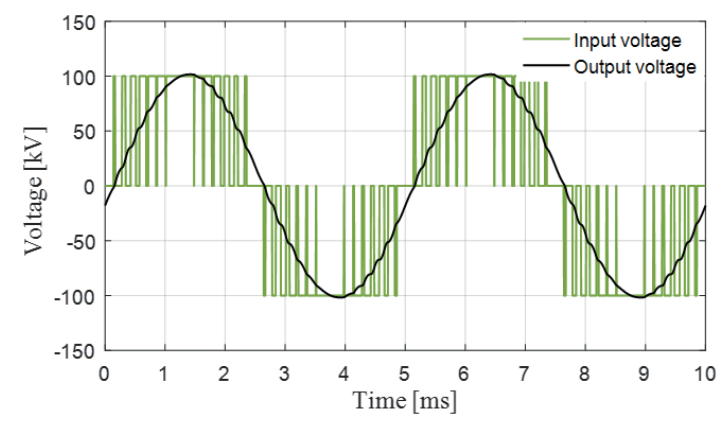

Fig. 11. (Color online) Input and output voltage waveforms.

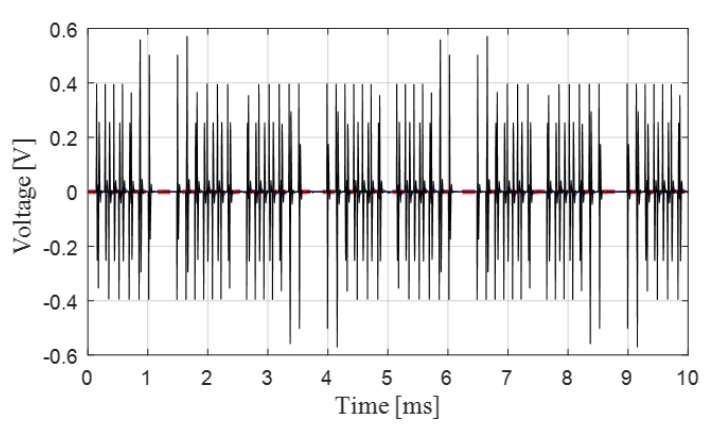

Fig. 12. (Color online) Voltage at the PD measuring port in the case of $100 \mathrm{kV}$ PWM voltage supplied to the system.

\subsection{Additional filter}

To reduce the noise signal generated by converter switching, an additional filter is required. The purposes of the filter are to remove undesired harmonic output voltages without attenuating the fundamental frequency voltage and to eliminate undesired interferences at the PD output port. In this work, the additional filter is composed of a resistor $\left(\mathrm{R}_{\mathrm{add}}\right)$, an inductor ( $\left.\mathrm{L}_{\mathrm{add}}\right)$, and a capacitor $\left(\mathrm{C}_{\mathrm{add}}\right)$. It is connected to the $\mathrm{LV}$ side of the testing transformer. In this study, this additional simple filter was selected for noise reduction. The performance of this filter is sufficient for reducing the background noise to the level suitable for the PD testing of all HV equipment. The equivalent circuit and the circuit parameters transferred to the HV side of the testing transformer are shown in Fig. 13. Note that the connected capacitances of 1 and $16 \mu \mathrm{F}$ on the LV side are equivalent to those of 0.038 and $0.6 \mathrm{nF}$ on the $\mathrm{HV}$ side.

The attenuation factor $\left(V_{P D} / V_{i n}\right)$ was calculated, and the result is shown in Fig. 14. It is noted from Figs. 9 and 14 that the additional filter with the additional capacitance of $16 \mu \mathrm{F}$ ( $0.6 \mathrm{nF}$ on the HV side) has promising characteristics. The cutoff frequency of the output voltage is around $900 \mathrm{~Hz}$, which is not greatly changed from that without the additional filter, and the maximum attenuation factor is $3.72 \times 10^{-8}$. Therefore, the voltage at the PD measuring port with the application of $100 \mathrm{kV}$ PWM input voltage is attenuated to be lower than $5 \mathrm{mV}$, which is lower than the voltage from the $2.5 \mathrm{pC}$ PD simulated pulse.

To confirm the validity of the additional filter, simulations in the time domain were carried out. The $100 \mathrm{kV}$ PWM input voltages with various switching frequencies from 1 to $20 \mathrm{kHz}$ and the modulation indexes of 0.8 and 1.0 were applied to the system. It was found that all interference voltages are lower than $5 \mathrm{mV}$, and all output voltages have $T H D_{v}$ of less than $0.2 \%$. Figures 15 and 16 show examples of the output voltage and the interference at the PD measuring port in the case of the switching frequency of $3.2 \mathrm{kHz}$ and the modulation index of 1.0. It is implied that the background noise of the system in PD measurement is lower than $2.5 \mathrm{pC}$ when a voltage of $100 \mathrm{kV}\left(70.7 \mathrm{kV}_{\mathrm{rms}}\right)$ is applied to the test object. 


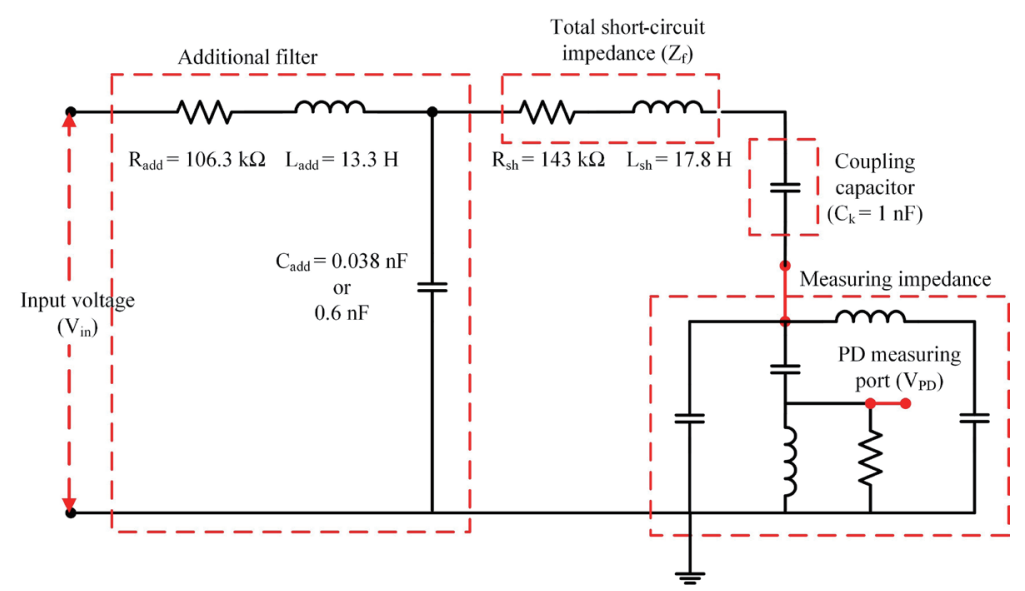

Fig. 13. (Color online) Equivalent circuit of the PD testing system with the additional filter.

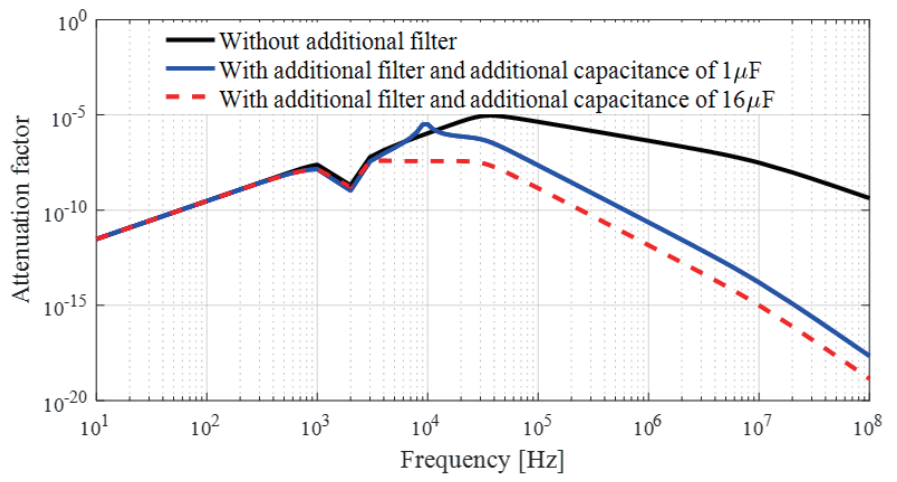

Fig. 14. (Color online) Attenuation factor with and without the additional filter.

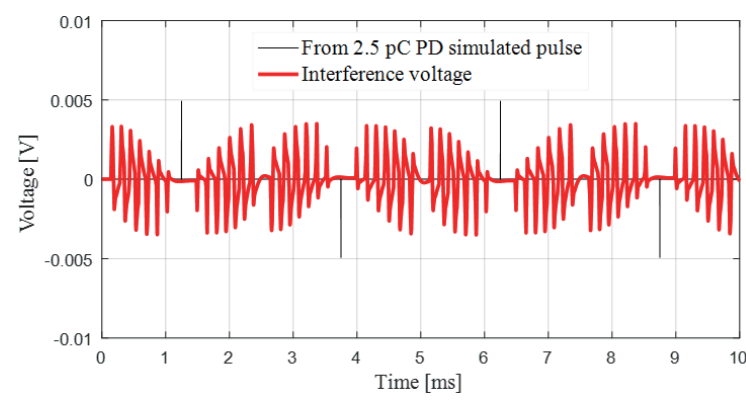

Fig. 15. (Color online) Voltage at the PD measuring port with a PWM voltage of $100 \mathrm{kV}$ supplied to the system.

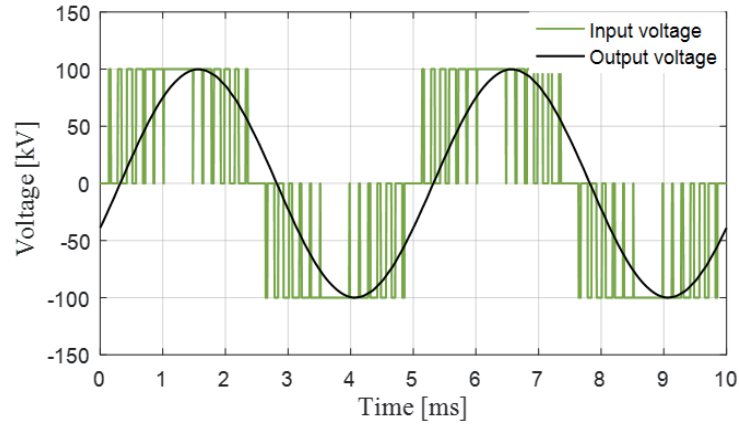

Fig. 16. (Color online) Input and output voltages with a PWM voltage of $100 \mathrm{kV}$ supplied to the system and the addition filter connected.

\section{Experiments}

Some experiments were carried out to investigate the performance of the developed system in the PD tests. The experimental setup is shown in Fig. 17. The circuit parameters were set to be almost the same as in Fig. 13. The effects of the switching frequency and $m_{a}$ were investigated. 


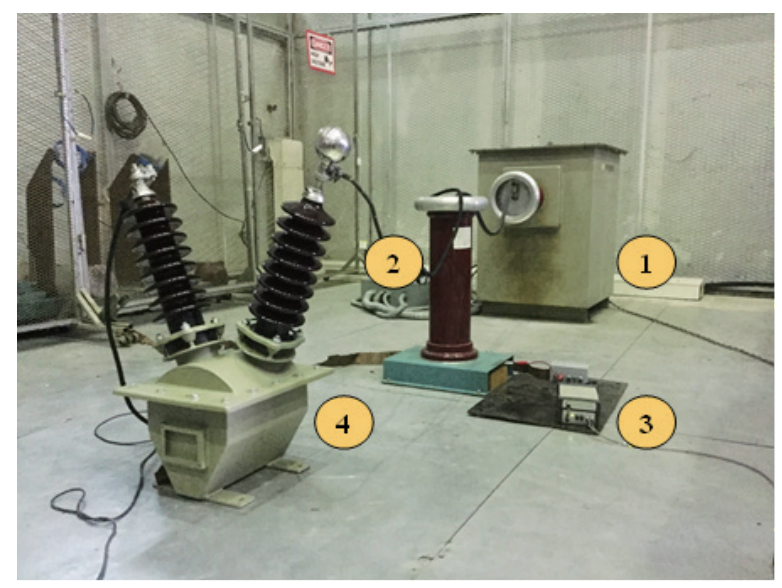

Fig. 17. (Color online) Experimental setup of the PD test with the PT. (1) HV testing transformer. (2) Coupling capacitor. (3) CD for PD detection. (4) PT under test.

The $D V, T H D_{v}$, and background noise in the PD tests were examined and measured using the developed system. To avoid the interference signal from electromagnetic coupling in the HV laboratory, commercial EO/OE converters (Omicron) ${ }^{(11)}$ with fiber optic cables were applied with the developed system. In the real PD test, the standard PD current with the charge of $5 \mathrm{pC}$ was utilized in the calibration process. The background noise obtained without the application of the developed inverter is less than $0.5 \mathrm{pC}$.

\subsection{Effect of additional capacitor $\left(\mathrm{C}_{\mathbf{a d d}}\right)$}

We should consider the test case in which the PWM voltage with the switching frequency of $3.2 \mathrm{kHz}$ and $m_{a}$ of 1.0 was applied to the LV side of the testing transformer. Without the additional filter, the background in the PD measurement at the testing voltage of only about $14 \mathrm{kV}$ is $162 \mathrm{pC}$, which is very high, as shown in Fig. 18. When the additional filter was connected to the system, the background noise was greatly reduced, as observed from the simulation results. In the case of the additional capacitor $\left(C_{a d d}\right)$ with 1 and $16 \mu F$, the background noise levels at the testing voltage of $40 \mathrm{kV}_{\mathrm{rms}}\left(70 \mathrm{kV}_{\mathrm{p}}\right)$ were reduced to be 18 and 2 pC, respectively. Some test results are shown in Figs. 19(a) and 19(b). It is confirmed that the appropriate capacitance is $16 \mu \mathrm{F}$.

\subsection{Experiment without test object}

In this part, the additional filter with the additional capacitance of $16 \mu \mathrm{F}$ was connected to the system, and there was no test object connected to the system during the experiment. The effects of switching frequency (1 to $20 \mathrm{kHz})$ and $m_{a}(0.8$ and 1.0) are investigated in terms of the background noise level, $T H D_{v}$, and input power consumption. In the experiment, the voltage was raised to $40 \mathrm{kV}_{\text {rms }}$ to imitate the prestress condition of the $24 \mathrm{kV}$ PT, then the voltage was 


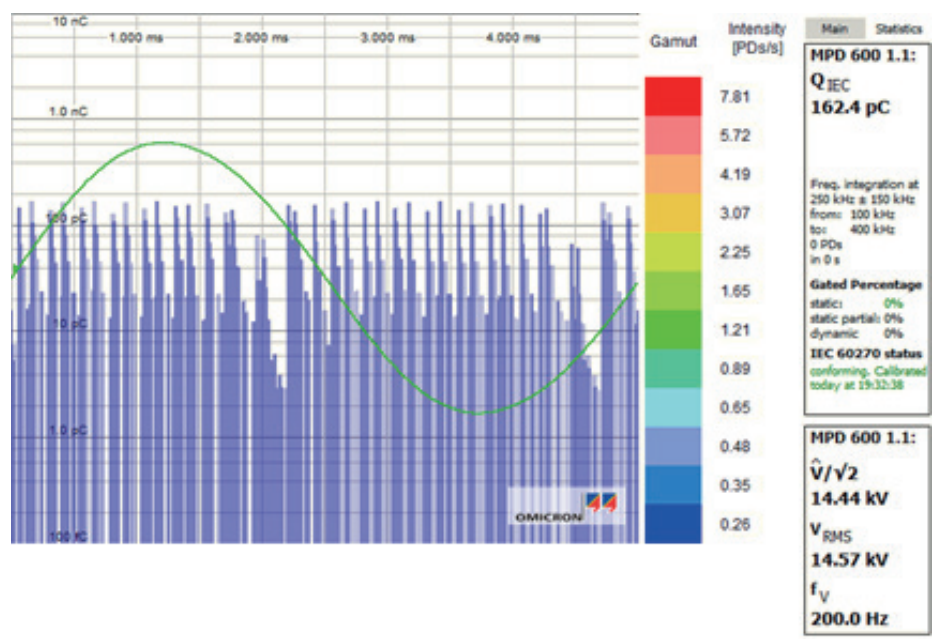

Fig. 18. (Color online) Experimental test results without the additional filter.

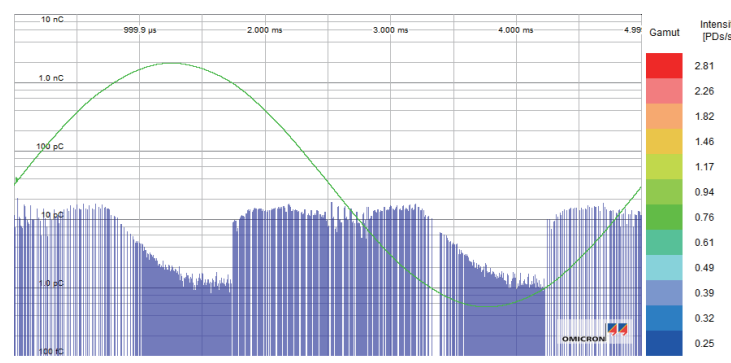

(a)

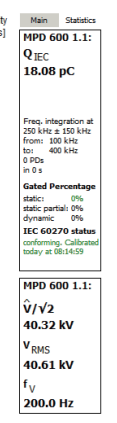

$\mathrm{I}_{\mathrm{V}} \mathrm{OW}$
$20 \mathrm{OHz}$

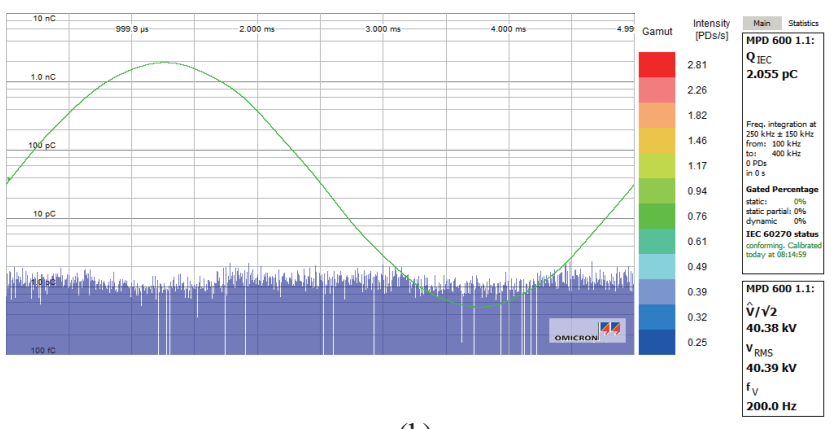

(b)

Fig. 19. (Color online) Experimental test results with the additional capacitances of (a) 1 and (b) $16 \mu \mathrm{F}$ and testing voltage of $40 \mathrm{kV}$.

reduced to $30 \mathrm{kV}_{\mathrm{rms}}$ to record the PD level. The experimental results are shown in Figs. 20-22. Also, some voltage waveforms and PD levels are shown in Figs. 23(a) and 23(b). It is found that the modulation index of 0.8 or 1.0 and the switching frequency do not greatly affect the PD level and $T H D_{v}$. All PD levels (less than $2.5 \mathrm{pC}$ ) and $T H D_{v}$ values (less than 5\%) are at acceptable levels. However, the input power consumption increases as the switching frequency increases. Therefore, from the experimental results, the appropriate switching frequency should be around 1 to $4 \mathrm{kHz}$.

\subsection{Experiment with PT}

To confirm the performance of the developed system in the PD test with a PT, the selected switching frequency of $2 \mathrm{kHz}$ and $m_{a}$ of 1.0 were employed to generate a voltage of $40 \mathrm{kV}_{\mathrm{rms}}$ for the prestress condition and a voltage of $30 \mathrm{kV}_{\mathrm{rms}}$ for recording the PD activity. In this case, a PT and the additional filter were connected to the system. The standard PD pulse with a charge of $5 \mathrm{pC}$ was used for calibration in the PD test. The experimental results at the testing voltage of about $30 \mathrm{kV}_{\mathrm{rms}}$ are shown in Fig. 24. 


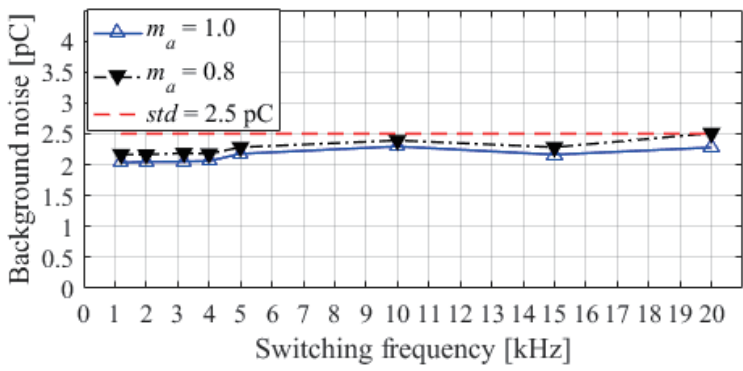

(a)

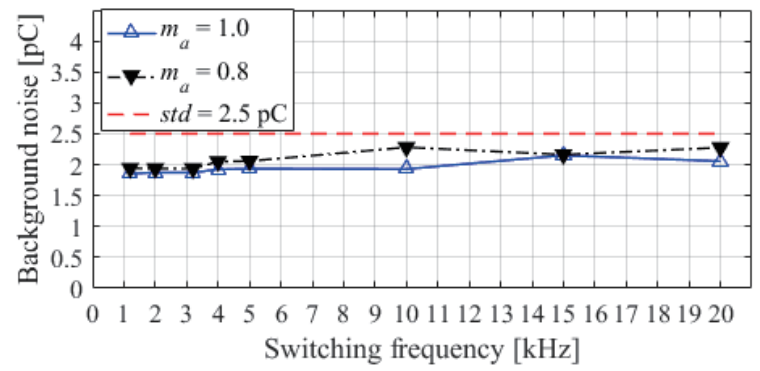

(b)

Fig. 20. (Color online) Background noise with switching frequency from 1 to $20 \mathrm{kHz}, m_{a}$ of 0.8 and 1.0, and testing voltages of (a) 40 and (b) $30 \mathrm{kV}_{\text {rms. }}$.

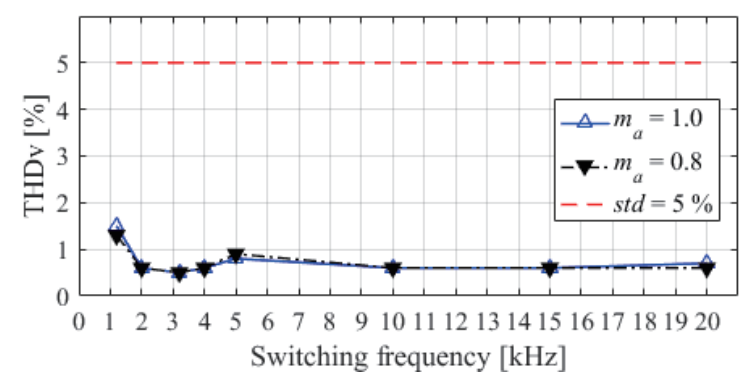

(a)

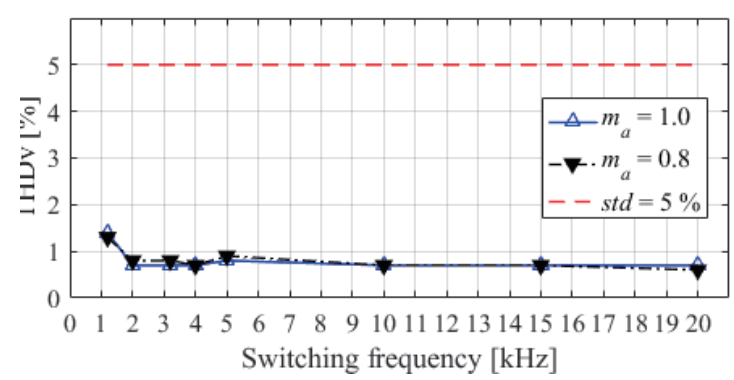

(b)

Fig. 21. (Color online) THDv with switching frequency from 1 to $20 \mathrm{kHz}, m_{a}$ of 0.8 and 1.0, and testing voltages of (a) 40 and (b) $30 \mathrm{kV}_{\text {rms. }}$.

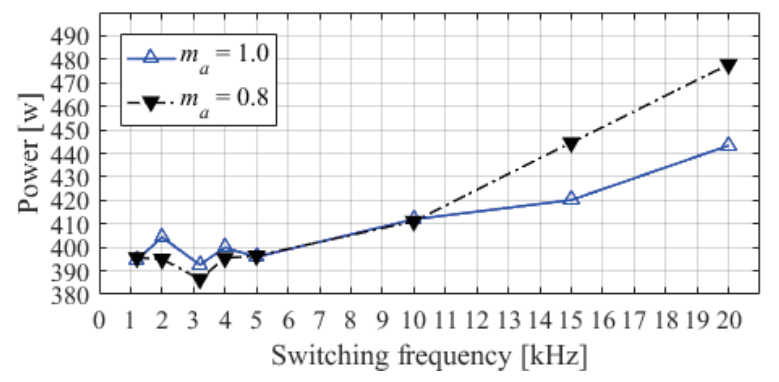

(a)

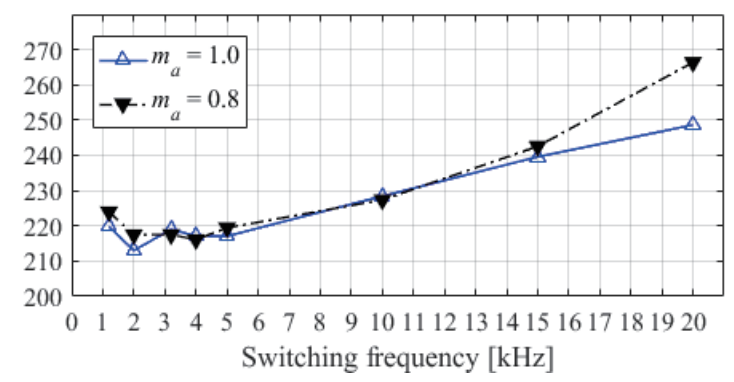

(b)

Fig. 22. (Color online) Input power consumption with switching frequency from 1 to $20 \mathrm{kHz}, m_{a}$ of 0.8 and 1.0 , and testing voltages of (a) 40 and (b) $30 \mathrm{kV}_{\text {rms. }}$.

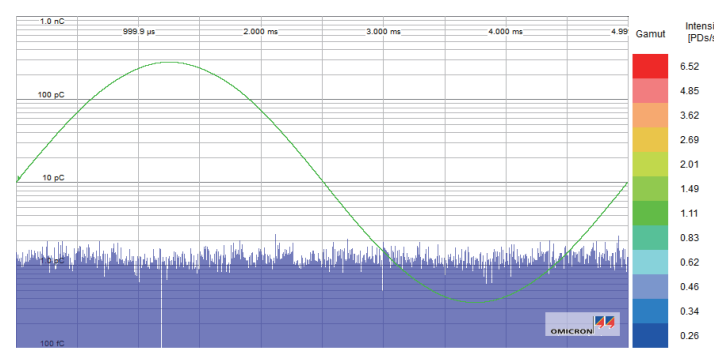

(a)
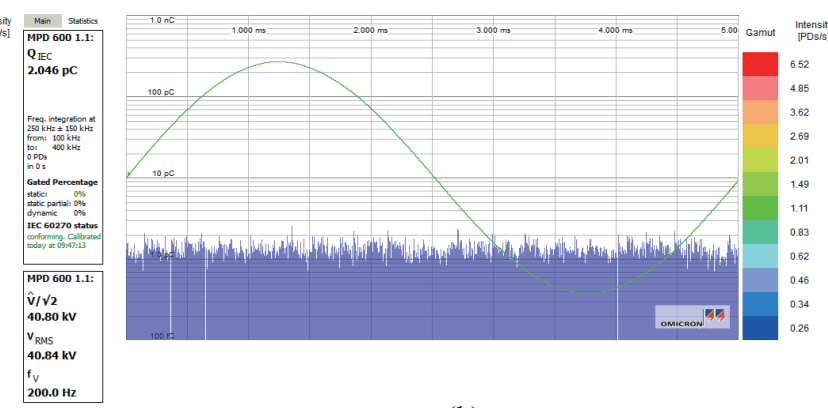

(b)

Fig. 23. (Color online) Output voltage waveform and PD level with switching frequency of $2 \mathrm{kHz}$, fundamental frequency of $200 \mathrm{~Hz}, m_{a}$ of (a) 1.0 and (b) 0.8 , and testing voltage of $40 \mathrm{kV}_{\mathrm{rms}}$. 


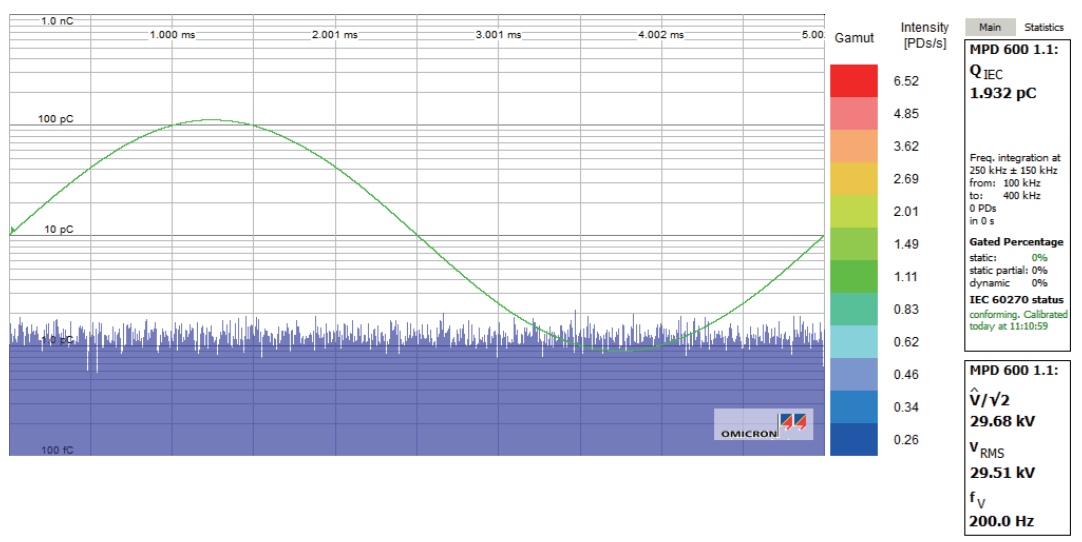

Fig. 24. (Color online) Experimental results with PT connected to the developed system.

From the experimental results, the difference voltage (peak voltage $/ \sqrt{2}=29.68 \mathrm{kV}$ and RMS voltage $=29.51 \mathrm{kV}$ ) was less than $1 \%$, the $T H D_{v}$ was less than $1 \%$, and the background noise was less than $2 \mathrm{pC}$.

\section{Conclusions}

The developed PD testing system based on the PWM frequency converter was presented. The unipolar PWM frequency converter with the proper low-pass filter showed promising performance in terms of $D V, T H D_{v}$, and background noise in the PD test. The $D V$ was less than $1 \%$, the $T H D_{v}$ was less than $1 \%$, and the background noise was less than $2.0 \mathrm{pC}$. In addition, the developed system was successfully used for the real PD test on a PT with the rating voltage of $24 \mathrm{kV}$. The developed system is an attractive choice for PD tests because of its high performance and low cost compared with the motor-generator system, and can be developed into a mobile system for PD tests in on-site inspections.

\section{Acknowledgments}

This work was financially and technically supported by the Faculty of Engineering, King Mongkut's Institute of Technology Ladkrabang.

\section{References}

1 High-Voltage Test Techniques: Partial Discharge Measurement, IEC Standard 60270: 2000.

2 IEEE STD98158 4-2013. IEEE Standard for High-Voltage Testing Techniques.

3 High-Voltage Test Techniques - Part 1 General definitions and test requirements: International Standard IEC 60060-1, 3rd ed. (Geneva, Switzerland, 2010).

4 D. G. Holmes and T. A. Lipo: Pulse Width Modulation for Power Converters, in Principles and Practice (John Wiley \& Sons, Inc., Jersey, 2003).

5 M. H. Rashid: Power Electronics Handbook (Butterworth-Heinemann, Massachusetts, 2011) 3rd ed.

6 A. Thiede1, and F. Martin: High-Volt Prüftechnik Dresden GmbH, Power Frequency Inverters for High Voltage Tests, High-Volt Colloquium, 2007. 
7 B. Leelachariyakul, P. Yutthagowith, and S. Potivejkul: PD Detection Test of a Voltage Transformer Using a Variable Frequency Converter (ISET, 2015).

8 Instrument Transformer-Part 1: General requirements, IEC Standard 61869-1: 2007.

9 Instrument Transformer-Part 3: Additional requirements for inductive voltage transformers, IEC Standard 61869-3: 2011.

10 W. Hauschild and E. Lemke: High-Voltage Test and Measuring Techniques (Springer, Heidelberg, 2014).

11 User manual for the device MPD600: https://www.omicronenergy.com (accessed Jan. 2019).

\section{About the Authors}

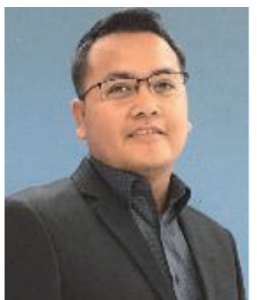

Tongpian Prombud received his B.Eng. and M.Eng. degrees from King Mongkut's Institute of Technology Ladkrabang, Thailand, in 2006 and 2012, respectively. From 2012 to the present, he has been with King Mongkut's Institute of Technology Ladkrabang as a Ph.D. student in the Department of Electrical Engineering. His research interests are in high-voltage engineering applications and sensors. (tongpian.p@gmail.com)

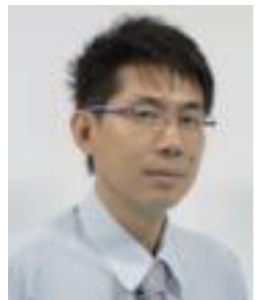

Peerawut Yutthagowith received his B.Eng. and M.Eng. degrees from Chulalongkorn University, Thailand, in 1998 and 2001, respectively and his Ph.D. degrees from Doshisha University, Japan, in 2010. From 2007 to the present, he has been with King Mongkut's Institute of Technology Ladkrabang. His research interests are in high-voltage engineering applications and sensors. (peerawut.yu@kmitl.ac.th) 